\title{
Astragalus IV ameliorates the dry eye injury in rabbit model via MUC1-ErbB1 pathway
}

\author{
Li Chu ${ }^{1 *}$, Suhong $\mathrm{Ma}^{2 *}$, Zhiwei Chen, ${ }^{3}$ Wenfu $\mathrm{Ca}^{3 *}$ \\ ${ }^{1}$ Chongqing Medical University, Jiulongpo District Traditional Chinese Medicine Hospital, Chongqing \\ ${ }^{2}$ Yunnan University of Chinese Medicine, Kunming, Yunnan \\ ${ }^{3}$ College of Traditional Chinese Medicine, Chongqing Medical University, Chongqing, China \\ *These authors contributed equally
}

\begin{abstract}
The therapeutic effects and potential mechanisms of astragaloside IV on a rabbits dry eye model induced by benzalkonium chloride (BAC) was examined. In our study, a BAC-induced dry eye rabbit model was treated with eye drops containing astragaloside IV $(5,10 \mu \mathrm{M})$ or solvent four times a day. The clinical evaluations, such as tear break-up time (BUT) and Schirmer tear test (STT), were performed on days 0, 7, 14, 21, and 28 . On day 28 , the cornea and bulbar conjunctiva tissues (left eye and right eye) were collected with histology, and immunofluorescent staining conducted. The levels of MUC1 and ErbB1in the corneas were determined by realtime quantitative PCR (qRT-PCR) and the proteins levels of MUC1 and ErbB1 were detected by Western blot. It was demonstrated that both astragaloside IV $(5,10 \mu \mathrm{M})$ treatments resulted in an increased STT and BUT on days 7, 14, 21 and 28. Additionally, the astragaloside IV $(5,10 \mu \mathrm{M})$-treated group showed increasing PAS-positive goblet cells than model group $(0 \mu \mathrm{M})$. Moreover, the MUC1 in model group $(0 \mu \mathrm{M})$ was decreased, while the expression of MUC1 in astragaloside IV $(5,10 \mu \mathrm{M})$ group was increased. Furthermore, astragaloside IV had a protective effect on BAC-induced rabbits' dry eye and demonstrated clinical improvements, which indicated that astragaloside IV served as a potential protective agent in the clinical treatment of dry eye.
\end{abstract}

Key words: Astragaloside IV; dry eye model; MUC1; ErbB1.

Correspondence: Wenfu Cao, College of Traditional Chinese Medicine, Chongqing Medical University, 400080, Chongqing, China. E-mail: wenfucao.CQMU@yandex.com

Contributions: LC, SM, carried out the experiments; WC, designed the study and edited the manuscript. All authors read and approved the final manuscript and agreed to be accountable for all aspects of the work.

Conflict of interest: The authors declare that they have no competing interests, and all authors confirm accuracy.

Availability of data and materials: All data are available from the corresponding authors on reasonable request.

Ethical Approval: The experiment was conducted in accordance with the National Institutes of Health Laboratory Animal Care and Use Guidelines (National Research Council, 1996, USA). 


\section{Introduction}

Dry eye disease has a complex etiology and it is an eye disease affecting the physical and mental health of $5-50 \%$ of the global population. ${ }^{1}$ Patients with dry eye disease often suffer ocular discomfort which leads to a lower quality of life. Aqueous deficient dry eye and evaporative dry eye are the most common causes of dry eyes. ${ }^{2}$ Aqueous deficiency affects the lacrimal gland, while evaporative dry eye is more associated with the eyelid (e.g., meibomian gland dysfunction and blink abnormalities) or the ocular surface (e.g., related to mucin deficiency or contact lens wear). ${ }^{3,4}$

Astragaloside IV is a single compound with CAS number 83207-58-3 and molecular weight 784.9702, high-purity drug extracted from Astragalus membranaceus, and is also known as "super Astragalus polysaccharide". Astragaloside IV enhances the body's immunity and improves the body's disease resistance. ${ }^{5}$ Moreover, astragaloside IV has been reported to inhibit migration and invasion of lung cancer cells $\mathrm{A} 549$ by regulating PKC- $\alpha$ ERK1/2-NF- $\kappa$ B. ${ }^{6}$ In addition, the anti-inflammatory effect of astragaloside IV is achieved by NF- $\kappa \mathrm{B}$ regulating inflammatory factors and adhesion molecule expression. ${ }^{7,8}$ The gene product of MUC1 transcription is cleaved after translation into two isolated proteins, which are bound together by non-covalent interactions. ${ }^{9}$ MUC1 is mainly found in cornea, conjunctival epithelial cells and tear fluid. ${ }^{10,11}$ Most O-glycosylation sites of MUC1 appear in a highly polymorphic core region with a variable number of tandem repeats. ${ }^{12}$ MUC1 can also inhibit tear evaporation. The absence and glycosylation of mucin can lead to the lack and denaturation of glycocalyx mucin barrier, which leads to the change of tear film on ocular surface and dry eye. The family of transmembrane tyrosine kinases, ErbB receptors are expressed dynamically during mammary gland development, ${ }^{9}$ while the dynamic expression is generally related to breast cancer in both humans and rodents. ${ }^{13}$ Overexpression of either the receptors or ligands in this family is usually presented at terminal metastatic disease and constantly leads to overall poor patient outcomes. ${ }^{14}$ ErbB1 can enhance the interaction between MUC1/CT and $\beta$-catenin and promote the entry of MUC1/CT- $\beta$-catenin complex into the nucleus. Astragaloside IV is mainly used in the treatment of inflammatory diseases due to the anti-inflammatory effect of AIV which were demonstrated by a reduction in pro-inflammatory cytokine levels via regulation of the IL- $1 \beta$, IL- 6, Ccl- 2 and TNF- $\alpha$ and these proteins expression..$^{7,13,15-17}$ In this study, the effect of astragaloside IV on BAC induced dry eye was comprehensively discussed from multiple perspectives. We believe that astragaloside IV may be a potential drug for the treatment of dry eye. This study investigated astragaloside IV's effect on cultured human corneal epithelial cells in vitro and evaluated whether its application could promote ocular surface health in an in vivo dry eye model.

\section{Materials and Methods}

\section{Animals}

In our research, 16 adult New Zealand White rabbits (male $=$ female $=8,2.5 \pm 0.5 \mathrm{~kg}$ ) without ocular abnormalities were conducted in accordance with the National Institutes of Health Laboratory Animal Care and Use Guidelines (National Research Council, 1996, USA). The normal control group consisted of four unoperated rabbits, and 12 rabbits were treated with $0.1 \%$ benzalkonium chloride in their eyes (BAC, Sigma-Aldrich, St. Louis, MO, USA) for 15 days. Three groups (four rabbits per group), namely model group $(0 \mu \mathrm{M})$, astragaloside IV (5 $\mu \mathrm{M}$, Sigma-Aldrich, St. Louis, MO, USA)-treated group, and astragaloside IV (10 $\mu \mathrm{M})$-treated group, were randomly made up of the rabbits with dry eye condition.

\section{Tear flow}

Schammer tear test (STT) was performed before and after treatment with astragaloside IV at $0,7,14,21$ and 28 days, the length of wetting was measured with a ruler with a gradient of $0.5 \mathrm{~mm}$.

\section{Break-up time (BUT)}

One $\mu \mathrm{L}$ of $0.1 \%$ liquid sodium fluorescein dropping into the conjunctival sac resulted in three blinks, which was recorded in seconds. Observe under a slit lamp microscope with cobalt blue light (CKX41; Olympus, Tokyo, Japan), until the first dryness appears on the tear film spot. The time was recorded from the eyelid opening to the appearance of the first dry spot and was measured three times in succession. The average value was taken and recorded.

\section{Microscopy}

Twenty-eight days later, all rabbits were killed by sodium pentobarbital overdose. As the cornea and bulbar conjunctiva tissue of both eyes were removed, aldehyde fixative was used to immerse them for light microscopy, followed by toluidine blue and basic fuchsin stained $1-\mu \mathrm{m}$-thick sections after preparation.

\section{qRT-PCR}

The TRIzol reagent (Invitrogen, Carslbad, CA, USA) was adopted to extract the total RNA of the corneas and a reverse transcription kit (RR047A; TaKaRa, Shiga, Japan) was used to synthesize cDNA. Through using a SYBR Premix Ex Taq Kit (RR420A; TaKaRa), realtime quantitative PCR was conducted based on a StepOne Real-Time PCR System (Applied Biosystems, Alameda, CA, USA) with its primer sequences summarized in Table 1 .

\section{Cell lines and treatments}

Human corneal epithelial cells (HCECs) belonged to a human SV40 immortalized corneal epithelial cell line (CRL-11135, HCE-2; ATCC, Manassas, VA, USA) between passages 25 and 30 . They were cultured in a medium containing $10 \%$ fetal bovine serum and 10 $\mathrm{ng} / \mathrm{mL}$ human epidermal growth factor. Later, $1 \mu \mathrm{g} / \mathrm{mL}$ of BCA was adopted to treat the immortalized HCECs to prepare a dry eye corneal epithelial cell injury model. The cells with dry eye condition randomly made up model group, astragaloside IV $(5 \mu \mathrm{M})$-treated group, and astragaloside IV $(10 \mu \mathrm{M})$-treated group.

\section{Determination of MUC1 level}

Human ELISA Development Kit (R \& D System, Inc., Minneapolis, MN, USA) was used to determine MUC1 level in the

Table 1. The primer sequences.

\begin{tabular}{|c|c|c|c|c|}
\hline Gene & Gene ID & & Primer sequences & Sequence length (bp) \\
\hline ACTB & NM_001101683.1 & $\begin{array}{l}\text { Forward: } \\
\text { Reverse: }\end{array}$ & $\begin{array}{l}\text { GATCAGCAAGCAGGAGTATGA } \\
\text { CGTTAGGTTTCGTCGAGAGAG }\end{array}$ & 112 \\
\hline $\mathrm{MUCl}$ & XM_017345830.1 & $\begin{array}{l}\text { Forward: } \\
\text { Reverse: }\end{array}$ & $\begin{array}{c}\text { ATGAGTGAGTACCCTACCTACC } \\
\text { CACTGCTGGATTCGTGTAAGA }\end{array}$ & 129 \\
\hline
\end{tabular}


culture medium according to the instructions. The culture medium was collected and centrifuged. Then, the supernatant was collected. The concentrations of MUC1 in the culture medium was calculated from a standard curve.

\section{HCECs transfection}

GenePharma (Shanghai, China) synthesized si-RNA and siMUC1. According to the manufacturer's instructions, si-RNA and siMUC1 $(50 \mathrm{nM})$ were transfected into HCECs by Lipofectamine 2000 (Invitrogen). After 2 days of growth, the original medium was discarded, and RPMI-1640 culture medium (Gibco, Gaithersburg, MD, USA) was selected to the transfected HCECs.

\section{Western blotting}

Firstly, corneal protein was extracted and the concentration of total protein of cell extract was measured with a protein detection kit. The membranes were incubated overnight at $4^{\circ} \mathrm{C}$ with rabbit antiMUC1 antibody (1:1000; Cell Signaling Technology, Danvers, MA, USA), rabbit anti-ErbB1 antibody (1:1000; Cell Signaling Technology), and horseradish peroxidase (HRP)-conjugated anti- $\beta$ actin antibody (1:20,000; Sigma-Aldrich) as a loading control The membranes were washed three times and incubated with HRP-conjugated goat anti-rabbit IgG (1:10,000; Sigma-Aldrich) for $1 \mathrm{~h}$.

\section{Hematoxylin and Eosin (HE) staining}

Fresh tissues were fixed with $4 \%$ formaldehyde, dehydrated and embedded, and then sliced. The paraffin sections were dewaxed with xylene and different concentrations of ethanol, and then put into hematoxylin dyeing solution for $8 \mathrm{~min}$. After washing with water, the paraffin sections were differentiated with hydrochloric acid ethanol for several s. $0.6 \%$ ammonia water turned blue and washed with running water. Then the paraffin sections were dyed in eosin dyeing solution for 1-3 min, dehydrated with ethanol and xylene and sealed with neutral resin.

\section{Immunofluorescence}

The tissue samples were embedded in paraffin and sectioned using a microtome (LeicaRM2235, Wentzler, Germany). Afterwards, the sections were incubated with an anti-MUC1 antibody (ab104978,1:500; Abcam, Cambridge, UK) overnight at $4^{\circ} \mathrm{C}$; then, the sections were incubated with a Cy3-labeled fluorescent secondary antibodies (1:500; Servicebio, Wuhan, China) for $50 \mathrm{~min}$ at room temperature. The nuclei were stained with DAPI. The staining was observed by an inverted phase contrast microscope (Olympus) equipped for fluorescence microscopy (DAPI was excited at 330-380 $\mathrm{nm}$ and emitted blue light; $\mathrm{Cy} 3$ was excited at 510-560 nm and emits red light). The fluorescence intensity was measured on images using Image Pro Plus 6.0.

\section{Statistical analysis}

We displayed the data with mean \pm SEM using SPSS22.0. The measurements were repeated at least three times and the paired $t$-test was used for statistical comparison.

\section{Results}

\section{Effect of the astragaloside IV on the Schirmer test}

The normal and model rabbits were treated with astragaloside IV and STT values were obtained after, as shown in Table 2. In the model $(0 \mu \mathrm{M})$ group, STT values were markedly decreased as compared to control group from 0 day to 28 days (all $\mathrm{p}<0.01$ ). The vehicle is unable to make the contralateral eye of model rabbits to produce tears like normal rabbit eyes, there was no increase in the eyes. STT values were increased significantly in astragaloside IV $(5 \mu \mathrm{M})$ from 14 days to 28 days after instillation compared with the model $(0 \mu \mathrm{M})$ group ( $<<0.05, p<0.01, p<0.01)$. STT values were also increased in astragaloside IV $(10 \mu \mathrm{M})$ from 7 days to 28 days compared with the model $(0 \mu \mathrm{M})$ group (all $\mathrm{p}<0.01)$. Maximal STT values occurred 28 days after instillation in astragaloside IV-treated $(10 \mu \mathrm{M})$ eyes $[17.87 \pm 1.44 \mathrm{~mm}($ mean $\pm \mathrm{SEM})]$.

\section{Effect of the astragaloside IV on the BUT}

As shown in Table 3, there was a general trend of decreasing BUT in the model $(0 \mu \mathrm{M})$ group as compared to the control group

Table 2. The values of Schirmer test in each group treatment with astragaloside IV ( $\mathrm{mm})$.

\begin{tabular}{lcccc} 
Group & Control & & Model & \\
& & $0 \mu \mathrm{M}$ & $5 \mu \mathrm{M}$ & 10 \\
$0 \mathrm{~d}$ & $15.87 \pm 1.12$ & $8.63 \pm 0.72^{*}$ & $8.87 \pm 0.22$ & $8.77 \pm 0.12$ \\
$7 \mathrm{~d}$ & $17.20 \pm 1.10$ & $8.57 \pm 0.80^{*}$ & $9.37 \pm 0.33$ & $10.89 \pm 1.01^{\S}$ \\
\hline $14 \mathrm{~d}$ & $17.53 \pm 1.03$ & $8.61 \pm 0.61^{*}$ & $10.87 \pm 1.00^{\sharp}$ & $13.87 \pm 1.13^{\S}$ \\
$21 \mathrm{~d}$ & $17.88 \pm 1.02$ & $8.59 \pm 0.54^{*}$ & $12.87 \pm 1.10^{\S}$ & $15.87 \pm 1.02^{\S}$ \\
\hline $28 \mathrm{~d}$ & $18.12 \pm 1.12$ & $8.62 \pm 0.83^{*}$ & $14.87 \pm 1.07^{\S}$ & $17.87 \pm 1.10^{\S}$ \\
\hline
\end{tabular}

${ }^{*} \mathrm{p}<0.01$ us Control group; ${ }^{\mathrm{p}} \mathrm{p}<0.05 ;{ }^{\mathrm{p}} \mathrm{p}<0.01$ us astragaloside IV $(0 \mu \mathrm{M})$.

Table 3. Values of BUT in each group treatment with astragaloside IV (s).

\begin{tabular}{|c|c|c|c|c|}
\hline Group & Control & $0 \mu \mathrm{M}$ & $\begin{array}{c}\text { Model } \\
5 \mu \mathrm{M}\end{array}$ & $10 \mu \mathrm{M}$ \\
\hline $00 \mathrm{~d}$ & $15.90 \pm 1.01$ & $8.60 \pm 0.52 *$ & $8.67 \pm 0.22$ & $8.57 \pm 0.12$ \\
\hline $7 \mathrm{~d}$ & $16.20 \pm 1.05$ & $8.47 \pm 0.60 *$ & $9.27 \pm 0.33$ & $10.79 \pm 1.01^{\#}$ \\
\hline $14 \mathrm{~d}$ & $16.53 \pm 1.09$ & $8.71 \pm 0.51 *$ & $10.97 \pm 1.00^{\#}$ & $12.99 \pm 1.13^{\S}$ \\
\hline $21 \mathrm{~d}$ & $16.48 \pm 1.15$ & $8.49 \pm 0.64^{*}$ & $12.65 \pm 1.10^{\S}$ & $14.47 \pm 1.02^{\S}$ \\
\hline $28 \mathrm{~d}$ & $16.62 \pm 1.13$ & $8.32 \pm 0.73 *$ & $14.33 \pm 1.07^{\S}$ & $16.89 \pm 1.10^{\S}$ \\
\hline
\end{tabular}

${ }^{*} \mathrm{p}<0.01$ us Control group; ${ }^{\circledR} \mathrm{p}<0.05 ;{ }^{\mathrm{s}} \mathrm{p}<0.01$ vs astragaloside IV $(0 \mu \mathrm{M})$. 
yet no statistically significant differences were found from 0 day to 28 days. The $5 \mu \mathrm{M}$ astragaloside IV treatment significantly increased BUT compared to the model $(0 \mu \mathrm{M})$ group on day 14,21 , 28. There also was an increase in BUT in the $10 \mu \mathrm{M}$ astragaloside IV-treated group on day 7, 14, 21, 28. Maximal BUT occurred 28 days after instillation in astragaloside IV-treated $(10 \mu \mathrm{M})$ eyes $[16.89 \pm 1.10 \mathrm{~s}($ mean \pm SEM) .

\section{HE staining of the effect of astragaloside IV on the cornea and bulbar conjunctiva tissue}

The results of HE staining of cornea and conjunctiva of rabbits showed that the color of the corneal extracellular matrix in dry eye model group was lighter than that in normal group because of dehydration, and the color of corneal matrix returned to normal after adding astragaloside IV. There was no significant difference between $5 \mu \mathrm{m}$ astragaloside IV and $10 \mu \mathrm{m}$ astragaloside IV. The number of goblet cells in conjunctival tissue of dry eye model group was significantly less than that of normal group. After adding astragaloside IV, the number of goblet cells in conjunctival tissue increased. There was no significant difference between $5 \mu \mathrm{m}$ astragaloside IV and 10um astragaloside IV. The results of HE staining were shown in Figure 1.

\section{Effect of astragaloside IV on the expression of MUC1 in cornea and bulbar conjunctiva tissue}

In order to find out how astragaloside IV influenced the expression of MUC1 in cornea and bulbar conjunctiva tissue,
ELISA, qRT-PCR, western blotting, and immunofluorescence staining for MUC1 in cornea and bulbar conjunctiva tissue were performed. The content of MUC1 in cornea and bulbar conjunctiva tissue of the model $(0 \mu \mathrm{M})$ group was obviously less than control group $(\mathrm{p}<0.001)$. The content of MUC1 in cornea and bulbar conjunctiva tissue of the astragaloside IV $(5,10 \mu \mathrm{M})$ gradually increased with the administration concentration, and was significantly higher than that of the model when the administration was $10 \mu \mathrm{M}(\mathrm{p}<0.001)$ (Figure 2A). At the same time, the results showed that mRNA and protein expression of MUC1 decreased in the model $(0 \mu \mathrm{M})$ group, but increased after the astragaloside IV $(5,10 \mu \mathrm{M})$ treatment (Figure $2 \mathrm{~B}-\mathrm{D})$. The expression of MUC1 was expressed by the intensity of red fluorescence, it is obvious from Figure $2 \mathrm{E}$, the red fluorescence intensity of $0 \mu \mathrm{M}$ group was significantly lower than that of the normal group, because there were fewer goblet cells and less MUCI secretion. After adding astragaloside IV, the red fluorescence intensity increased, indicating that MUCI secretion was more. There was no difference in the red fluorescence intensity between groups $5 \mu \mathrm{M}$ and $10 \mu \mathrm{M}$ group, indicating that the expression of MUC1 in these two groups was similar (Figure 2E).

\section{Effect of astragaloside IV on the MUC1-ErbB1 activation}

qRT-PCR and Western blotting analysis were respectively used to study the activation of ErbB1 (Figure 3). The study revealed that in the control siRNA groups, BAC induction decreased the mRNA
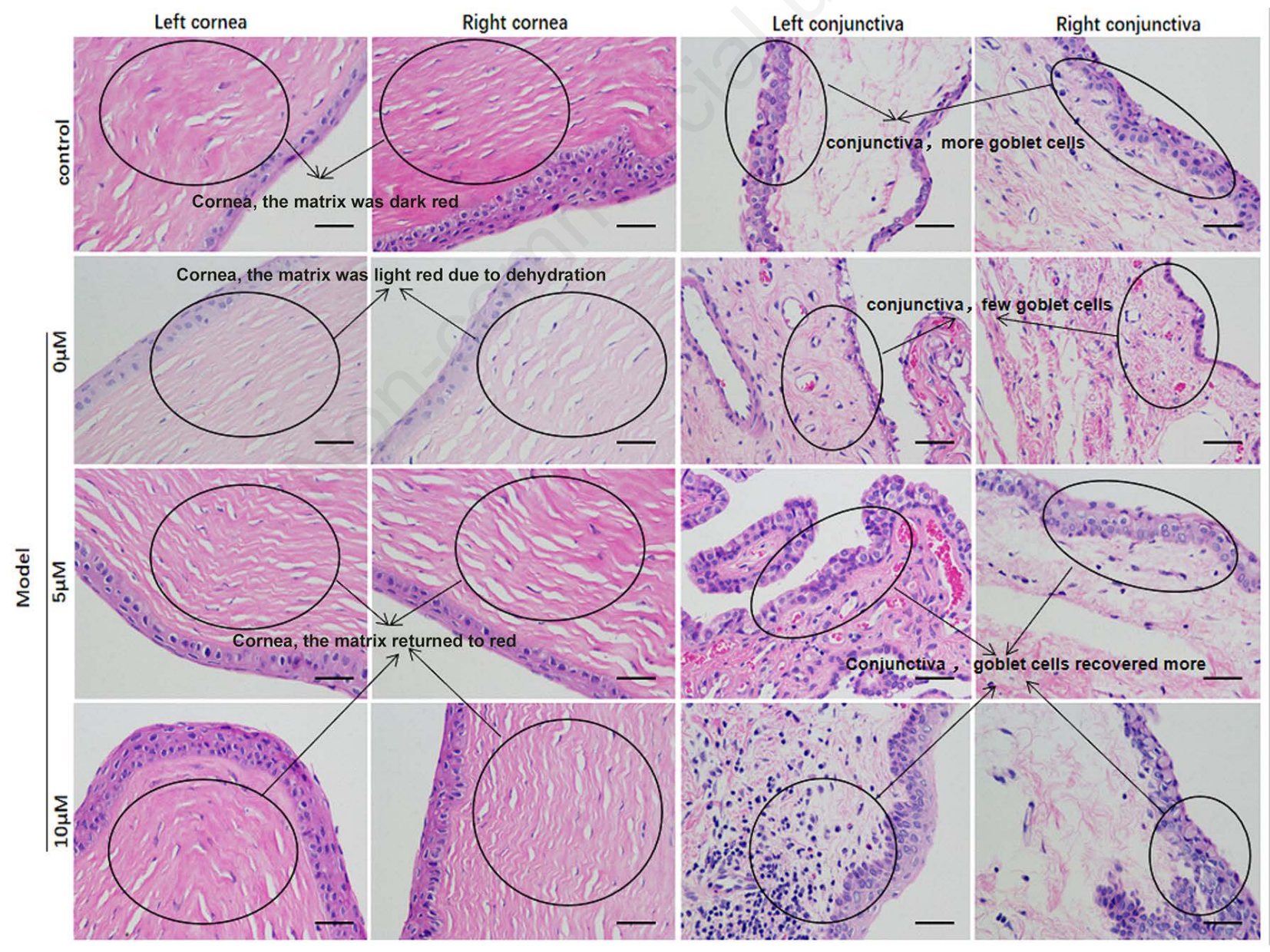

Figure 1. Effects of different concentrations of astragaloside IV on cornea and conjunctiva of dry-eye rabbit. Scale bars: $100 \mu \mathrm{m}$. 

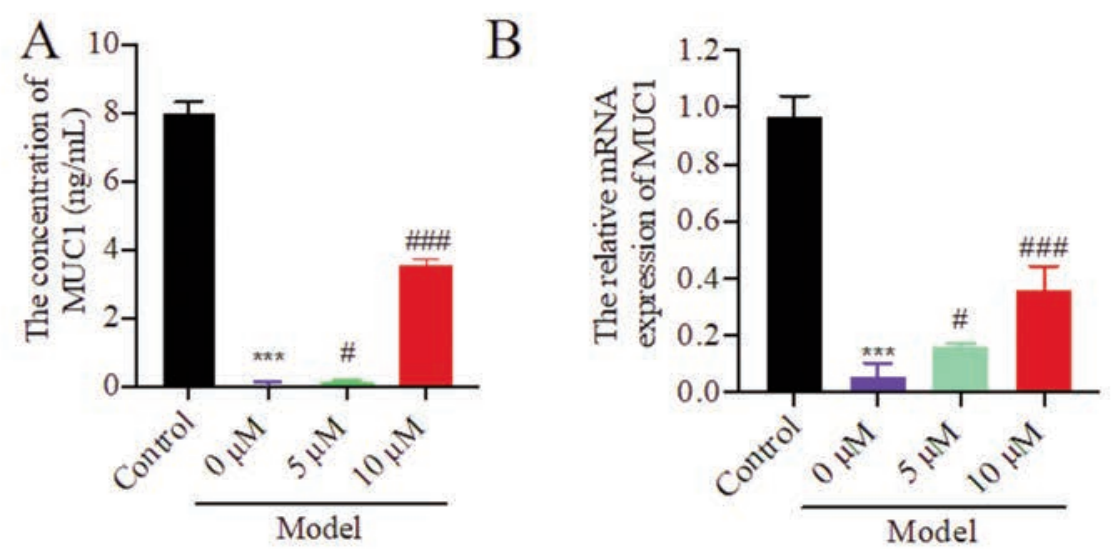

C
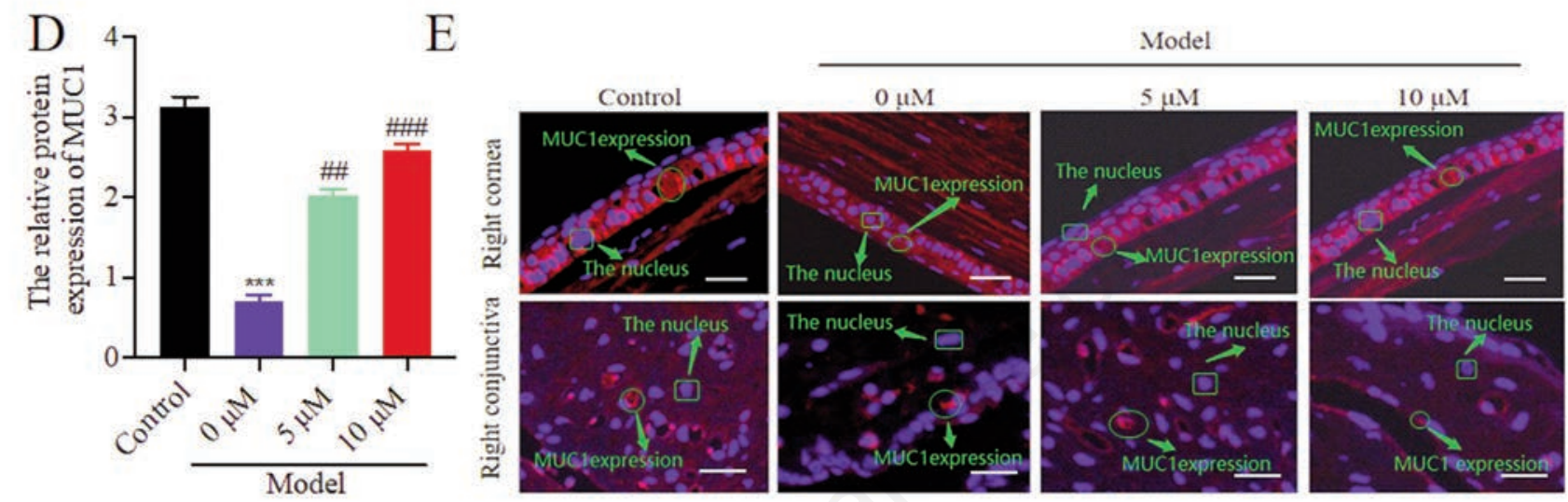

Figure 2. Effect of astragaloside IV on the expression of MUC1 in the cornea and conjunctival tissue. A) The concentration of MUC1 (ng/mL) was evaluated by ELISA. B) The relative mRNA of MUC1 was evaluated by $\mathrm{qRT}-\mathrm{PCR}$. C,D) The relative protein expression of MUC1 was evaluated by Western blot. E) Immunofluorescence detection of the expression of MUC1. Scale bars: $100 \mu \mathrm{m}$. ${ }^{* * *} \mathrm{p}<0.001$ vs Control group, ${ }^{\#} \mathbf{p}<0.05,{ }^{\#} \mathrm{p}<0.01$ and ${ }^{\# \# \#} \mathrm{p}<0.001$ vs astragaloside IV $(0 \mu \mathrm{M})$.
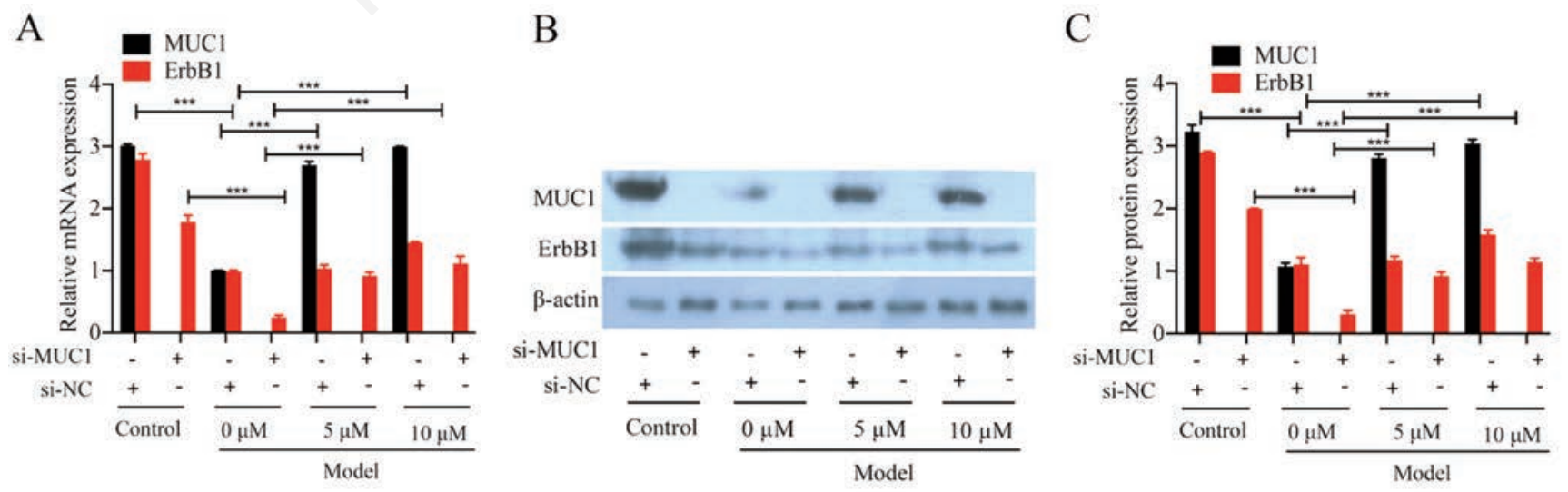

Figure 3. Effect of astragaloside IV on the MUC1-ErbB1 activation in the corneas. A) The relative protein expression of MUC1 and ErbB1 was evaluated by qRT-PCR. B,C) The relative protein expression of MUC1 and ErbB1 was evaluated by Western blot. ${ }^{* * *} \mathbf{p}<0.001$. 
and protein of MUC1 and ErbB1 expressions in model $(0 \mu \mathrm{M})$ group, as with those in the control group in contrast. However, the mRNA and protein of MUC1 and ErbB1 expressions were promoted significantly in both astragaloside IV $(5,10 \mu \mathrm{M})$-treated groups. The expression of MUC1 in HCECs was reduced transiently when RNAi (siRNA) was used. Cells transfected with MUC1 siRNA reduced erbB1 mRNA and protein expressions in all groups, the mRNA and protein expressions of ErbB1 were markedly decreased as compared to those in control siRNA groups. This loss of MUC1 correlates with a significant loss of ErbB1 expressions indicating that MUC1 as a potentially critical mediator of erbB1 stability and function, one that may have dramatic implications for erbB1-mediated dry eye.

\section{Discussion}

Astragaloside IV has a single component, which is clearer than many traditional Chinese medicine compounds and has a clear curative effect. It has good biological activity, anti-bacterial, antiinflammatory and anti-virus antibacterial, antiinflammatory and antiviral activity, can improve immunity, and is less toxic to liver and kidney than same Western medicines. However, it has been reported that astragaloside IV has genotoxicity, and the lead content in most astragaloside IV samples exceeds the standard, so it is forbidden for pregnant women.

In the present study, astragaloside IV $(5,10 \mu \mathrm{M})$ increased STT and BUT in vivo. The results of STT and BUT were the same as previously reported after topical doxycycline, ${ }^{18}$ cyclosporine, ${ }^{19}$ or uridine ${ }^{20}$ administration. Ocular surface mucin (MUC) is a type of high molecular weight glycosylated protein secreted by goblet cells and non-goblet epithelial cells of conjunctival tissue. ${ }^{21}$. There are currently 7 types of MUCs present on the ocular surface, namely MUC1, MUC2, MUC4, MUC5AC, MUC5B, MUC7 and MUC16. ${ }^{22}$ Amongst them, MUC1 is the first mucin that was confirmed to be located on the ocular surface, secreted by goblet cells, it is also the main component of the mucin layer in the tear film. ${ }^{23}$ Dry diseases of the ocular surface often lead to a decrease in numbers of goblet cells, which in turn affects MUC synthesis and secretion. ${ }^{24,25}$ It is difficult to restore the stability of the tear film simply by supplementing ocular surface water. Therefore, based on effectively promoting tear secretion, it is possible to increase ocular surface viscosity. ${ }^{26,27}$ The synthesis and expression of protein are important prerequisites for restoring ocular surface health. ${ }^{28}$ In BAC-induced dry eye model, the expression of MUC1 was decreased but was increased after astragaloside IV treatments.

According to previous investigations, transmembrane MUCs interacted with members of the ErbB family. ${ }^{29}$ A co-immunoprecipitation between ErbB2 and MUC4 (ASGP1 and -2) in both the metastatic ascites 13762 rat mammary carcinoma cell line as well as the pregnant rat had already been confirmed by Schroeder et al. ${ }^{9}$ The presence of MUC1 in immunoprecipitations is due to heterodimerization complexes between the four ErbB receptors and MUC1. ${ }^{30}$ Previous study indicated that all ErbB receptors can be turned into transphosphorylase, which revealed that these complexes formed in this phase. ${ }^{31}$ It can be comprehended from experiments that induction of BAC inhibits activation of ErbB1, which was increased by astragaloside IV. As cells transfected with MUC1 siRNA showed a loss of ErbB1 in all groups, the expressions of ErbB1 were markedly decreased as compare to those in control siRNA groups. We suggest that MUC1 may be a key mediator for the stability of ErbB1 and thus has an important effect on ErbB1mediated dry eye.

In summary, our study showed that astragaloside IV improves the clinical efficacy to a certain extent by increasing the expression of MUC1 in dry eyes induced by $0.1 \%$ BAC. However, the safety of astragaloside IV for the treatment of dry eye disease requires further evaluation.

\section{References}

1. Calonge M, Enríquez-de-Salamanca A, Diebold Y, GonzálezGarcía MJ, Reinoso R, Herreras JM, et al. Dry eye disease as an inflammatory disorder. Ocul Immunol Inflamm 2010;18: 244-53.

2. Craig JP, Nelson JD, Azar DT, Belmonte C, Bron AJ, Chauhan SK, et al. The TFOS dry eye workshop II: executive summary. Ocul Surf 2017;15:802-12.

3. Kovács I, Luna C, Quirce S, Mizerska K, Callejo G, Riestra A, et al. Abnormal activity of corneal cold thermoreceptors underlies the unpleasant sensations in dry eye disease. J Pain 2016;157:399-417.

4. Craig JP, Nichols KK, Akpek EK, Caffery B, Dua HS, Joo CK, et al. TFOS DEWS II definition and classification report. Ocul Surf 2017;15:276-83.

5. You H, Lu Y, Gui D, Peng A, Chen J, Gu Y. Aqueous extract of Astragali Radix ameliorates proteinuria in adriamycin nephropathy rats through inhibition of oxidative stress and endothelial nitric oxide synthase. J Ethnopharmacol 2011;134:176-82.

6. Cheng X, Gu J, Zhang M, Yuan J, Zhao B, Jiang J, et al. Astragaloside IV inhibits migration and invasion in human lung cancer A549 cells via regulating PKC- $\alpha$-ERK1/2-NF- $\kappa$ B pathway. Int J Immunopharmaco 2014;23:304-13.

7. Gui D, Huang J, Guo Y, Chen J, Chen Y, Xiao W, et al. astragaloside IV ameliorates renal injury in streptozotocin-induced diabetic rats through inhibiting NF- $\mathrm{kB}-$ mediated inflammatory genes expression. Cytokine 2013;61:970-7.

8. Zhang WJ, Hufnagl P, Binder BR, Wojta J. Antiinflammatory activity of astragaloside IV is mediated by inhibition of $N F-\kappa B$ activation and adhesion molecule expression. Thromb Haemost 2003;89:904-14.

9. Schroeder JA, Thompson MC, Gardner MM, Gendler SJ. Transgenic MUC1 interacts with epidermal growth factor receptor and correlates with mitogen-activated protein kinase activation in the mouse mammary gland. J Biol Chem 2001;276:13057-64.

10. Imbert Y, Darling DS, Jumblatt MM, Foulks GN, Couzin EG, Steele PS, et al. MUC1 splice variants in human ocular surface tissues: possible differences between dry eye patients and normal controls. Exp Eye Res 2006;83:493-501.

11. Inatomi T, Spurr-Michaud S, Tisdale AS, Zhan Q, Feldman ST, Gipson IK. Expression of secretory mucin genes by human conjunctival epithelia. Invest Ophth Vis Sci 1996;37:1684-92.

12. Spicer AP, Parry G, Patton S, Gendler SJ. Molecular cloning and analysis of the mouse homologue of the tumor-associated mucin, MUC1, reveals conservation of potential O-glycosylation sites, transmembrane, and cytoplasmic domains and a loss of minisatellite-like polymorphism. $\mathrm{J}$ Biol Chem 1991;266:15099-109.

13. Siegel PM, Ryan ED, Cardiff RD, Muller WJ. Elevated expression of activated forms of Neu/ErbB-2 and ErbB-3 are involved in the induction of mammary tumors in transgenic mice: implications for human breast cancer. Embo J 1999;18:2149-64.

14. Onn A, Correa AM, Gilcrease M, Isobe T, Massarelli E, Bucana CD, et al. Synchronous overexpression of epidermal growth factor receptor and HER2-neu protein is a predictor of 
poor outcome in patients with stage I non-small cell lung cancer. Clin Cancer Res 2004;10:136-43.

15. Qi Y, Gao F, Hou L, Wan C. Anti-inflammatory and immunostimulatory activities of astragaloside IVs. Am J Chinese Med 2017;45:1157-67.

16. Yang J, Wang HX, Zhang YJ, Yang YH, Lu ML, Zhang J, et al. astragaloside IV attenuates inflammatory cytokines by inhibiting TLR4/NF-кB signaling pathway in isoproterenol-induced myocardial hypertrophy. J Ethnopharmacol 2013;150:106270 .

17. Zhou X, Sun X, Gong X, Yang Y, Chen C, Shan G, et al. astragaloside IV from Astragalus membranaceus ameliorates renal interstitial fibrosis by inhibiting inflammation via TLR4/NFкВ in vivo and in vitro. Int Immunopharmacol 2017;42:18-24.

18. Zhang Z, Yang WZ, Zhu ZZ, Hu QQ, Chen YF, He H, et al. Therapeutic effects of topical doxycycline in a benzalkonium chloride-induced mouse dry eye model. Invest Ophth Vis Sci 2014;55:2963-74.

19. Toshida H, Nguyen DH, Beuerman RW, Murakami A. Neurologic evaluation of acute lacrimomimetic effect of cyclosporine in an experimental rabbit dry eye model. Invest Ophth Vis Sci 2009;50:2736-41.

20. Oh JY, In YS, Kim MK, Ko JH, Lee HJ, Shin KC, et al. Protective effect of uridine on cornea in a rabbit dry eye model. Invest Ophth Vis Sci 2007;48:1102-9.

21. Gipson IK. Distribution of mucins at the ocular surface. Exp Eye Res 2004;78:379-88.

22. Gipson IK, Argueso P. Role of mucins in the function of the corneal and conjunctival epithelia. Int Rev Cytol 2003;231:1-49.
23. Watanabe H. Significance of mucin on the ocular surface. Cornea 2002;21:S17-22.

24. Baudouin C, Rolando M, Del Castillo JMB, Messmer EM, Figueiredo FC, Irkec M, et al. Reconsidering the central role of mucins in dry eye and ocular surface diseases. Prog Retin Eye Res 2019;71:68-87.

25. Johnson ME, Murphy PJ. Changes in the tear film and ocular surface from dry eye syndrome. Prog Retin Eye Res 2004;23:449-74.

26. Albietz JM. Dry eye: an update on clinical diagnosis, management and promising new treatments. Clin Exp Optom 2001;84:4-18.

27. Zhang X, Qu Y, He X, Ou S, Bu J, Jia C, et al. Dry eye management: targeting the ocular surface microenvironment. Int $\mathrm{J}$ Mol Sci 2017;18:1398.

28. Wolosin JM, Budak MT, Akinci MAM. Ocular surface epithelial and stem cell development. Int J Dev Biol 2004;48:981-91.

29. Carraway KL, Ramsauer VP, Haq B, Carothers Carraway CA. Cell signaling through membrane mucins. Bioessays 2003;25:66-71.

30. Li Y, Yu WH, Ren J, Chen W, Huang L, Kharbanda S, et al. Heregulin targets $\gamma$-catenin to the nucleolus by a mechanism dependent on the DF3/MUC1 oncoprotein. Mol Cancer Res 2003;1:765-75.

31. Muraoka-Cook RS, Feng SM, Strunk KE, Earp HS ErbB4/HER4: role in mammary gland development, differentiation and growth inhibition. J Mammary Gland Biol Neoplasia 2008;13:235-46.

Received for publication: 11 November 2020. Accepted for publication: 18 February 2021.

This work is licensed under a Creative Commons Attribution-NonCommercial 4.0 International License (CC BY-NC 4.0).

(C) Copyright: the Author(s), 2021

Licensee PAGEPress, Italy

European Journal of Histochemistry 2021; 65:3198

doi:10.4081/ejh.2021.3198 